\title{
LETTERS
}

Send your letters to the editor, British Dental

Journal, 64 Wimpole Street, London W1G 8YS or email bdj@bda.org

Priority will be given to letters less than 500

words long. Authors must sign the letter,

which may be edited for reasons of space

\section{Coagulopathies from drugs}

Sir,- My wife, a dental practitioner has drawn my attention to this article, (BDJ 2003, 195: 495) which I find extremely comprehensive. My interest is that, as a retired consultant accident and emergency surgeon (or ER physician in the US) I have bouts of supraventricular tachycardia or atrial fibrillation following quadrupal coronary artery bypass grafting nine years ago. I had the unfortunate experience of being allergic to warfarin following my first coronary thrombosis, so I have to use a very obscure coumarin derivative, phenindione (phenyl-indane-dione).

I do not know if this is licensed by the Food and Drug Administration (FDA), but it keeps me free of thrombotic episodes, and apparently works in the same way as warfarin, enough to continue in medical activities in a less stressful field. It might be an idea to include this drug in any further survey.

\section{Flowers}

By email

One of the authors of the paper P.B. Lockhart replies: I would like to thank Dr Flowers for his addition to our paper. I looked up phenindione (dindevan) in our drug text and did not find it. This does not mean that it is not an FDA approved drug under another name and in limited use in the US, but our cardiologist did not recognize it and he should know. I looked it up in the British National Formulary and it appears to have the same precautions as warfarin and therefore I suspect it should be thought of in the same way from the standpoint of bleeding from invasive dental procedures.

doi: 10.1038/sj.bdj.4811088

Sir,- The article (BDJ 2003, 195: 495) is, regarding table 3 , incorrect and referring to references not applicable to current UK (medical) practice. Since 1998 the British Society for Haematology, third edition, Guidelines on oral coagulation (British Journal of Haematology 1998, 101: 374387) are widely used. These guidelines recommend using target values rather than ranges ${ }^{1}$. The target values are summarized in a more easily readable format in the $\mathrm{BNF}^{2}$. In general, most patients presenting to a GDP will have a target value of 2.5, a small minority might have a target value of 3.5 (in case of having a mechanical prosthetic heart valve or recurrent thrombo-embolism). In contrast to what is suggested in the table, it is not common practice in the UK for patients to be warfarinised after myocardial infarction, nor after a CVA/TIA unless also in atrial fibrillation. Patients with bioprosthetic heart valves do not receive anticoagulation in the UK.

\section{P. Nederlof}

Gloucestershire

1. www.bcshguidelines.com

2. British National Formulary 46, September 2003

One of the authors of the paper P.B.

Lockhart replies: Dr Nederlof is, of course, correct about the UK having targets rather than ranges for INR levels since 1998, although the current BNF still offers a range of 'INR 2-2.5 for prophylaxis of deep-vein thrombosis including surgery on high-risk patients' (British National Formulary 46, September 2003, p115). Our paper should, more helpfully, have pointed this out to a UK readership where the table would have indicated 'Target INR value lies within the given range'.

However, table 3 was merely an attempt to indicate the differing ranges of INR values throughout medical practice across several countries. It was not designed to be prescriptive in a UK, or other national, context.

Concerning his comment about warfarin and MI patients, our table states 'some patients...following acute MI' and 'some MI patients.' We listed CVA and TIA for completeness sake for dentists who need to be aware of the potential reasons for patients being on warfarin.

The table does not imply that these uses are 'common practice' either in the UK or elsewhere. Finally, table 3 does not mention bioprosthetic heart valves. They are not covered with warfarin in the US either.

doi: 10.1038/sj.bdj.4811089

\section{Atkins diet}

Sir,- I thank Dr's Beeley and Ahearne (BDJ 2003, 195: 483) for responding through your columns to my letter asking if any colleagues had noticed increased calculus deposition in patients on the Atkins diet (BDJ 2003, 195: 231).

Their suggestions for a biochemical cause of this phenomenon, mediated either metabolically or through the action of bacteria, are valuable additions to the debate and I have received a similar suggestion personally from Dr Suren Perera. I have seen a further few cases and have noticed that there doesn't seem to be any increase in calculus buccal to the upper molars adjacent to the opening of the parotid duct.

This suggests that the problem is unlikely to be of biochemical origin unless there is a substantial difference in calcium content between saliva from the parotid and the other salivary glands. Perhaps an academic colleague may be able to shed light on this. The patients seem convinced that the problem is mechanical due to decreased roughage in their diet with a consequent reduction in self-cleaning.

\section{B. Skinner \\ London}

doi: 10.1038/sj.bdj.4811090

\section{Primary dentition}

Sir,- It is disturbing to read once again an article questioning the appropriateness of carrying out restorative treatment for children with caries in their primary dentition (BDJ 2003, 195: 301).

I have worked in the Community Dental Service for the past 10 years and over the years the number of children referred by GDPs for restorative care of the primary dentition has increased dramatically. If according to the above authors, GDPs have learned experimentally how to deal with the problem of caries in the primary dentition then why are Community Dental Services being overloaded by referrals from GDPs?

Whilst I accept that the Manchester studies show not all carious teeth cause trouble, these are retrospective studies and 
they do demonstrate a high level of morbidity associated with carious primary molars (65\%). In any sphere of medicine, would a physician or surgeon advocate non-treatment for an irreversible pathological condition with a high morbidity where effective treatment interventions exist?

I agree with the authors that at present the available evidence does not support the restoration of all carious primary teeth but equally the evidence given by authors certainly does not support non-restoration of all primary teeth, which is the interpretation that many primary care dentists will infer from this article. The recent studies by Manchester including this current article demonstrate that the care provided by GDPs in the north west is ineffective and makes no difference to outcome. How can such a study then say ultimately that what matters is the best interest of children and that this approach puts the child before the tooth?

I would also like to comment with regard to traumatizing young children. I believe that if treatment for children is provided appropriately then most children in my experience become dramatically more positive about their dental health and it is usually the child in acute pain that ends up having a bad experience. When resources are limited choices have to be made, but this is a decision for politicians and as a clinician there should be one standard of care that produces the best outcome for the patient.

\section{J. Tahmassebi}

\section{North Yorkshire}

The authors of the paper K.M. Milsom, $M$. Tickle and D. King respond: It is not for the authors to comment on the referral patterns of GDPs in Manchester. Why GDPs refer children into the Community Dental Service for the restorative treatment of the primary dentition is presumably a matter for local determination, although it would be interesting to know what service the CDS delivers to these children that cannot be delivered in the GDS.

The authors are not advocating nontreatment, or non-restoration but merely pointing out that the outcomes associated with restored carious primary molars are similar to those associated with a nonrestorative approach. Further we believe that there is a high success rate within the GDS, given that over $80 \%$ of carious molars restored or not, exfoliate without giving pain. Contrary to what the respondent believes, the data suggest that GDPs are effective in their care of the primary dentition, without following the guidance set out by the BSPD. It is a matter of concern that almost half of the children in the study experienced at least one episode of dental pain, and that the greater the decay experience, the greater was the likelihood of them having dental pain, but this finding points to the need for effective prevention of dental caries, not increased dental restoration.

Finally the respondent claims that children treated appropriately become positive about their dental health. The authors support this position and urge that the profession turns its attention to identifying what is meant by the term 'appropriate'. Currently we are unsure. doi: 10.1038/sj.bdj.4811091

\section{DIY dentistry UK style}

Sir,- I was interested in the letter (BDJ 2003 195: 361) on do-it-yourself dentistry. As we all know lost anterior teeth can be a real aesthetic problems for patients. I recently saw a 36-year-old lady who had lost the UL1 and UL2 (figure 1).

Surprisingly she had constructed a removable device made out of foil and cardboard (figure 2) to close the gap for the missing teeth, although this could not be used for mastication.

She seemed comfortable with this device but was very happy when I offered to provide her with a partial denture to replace the missing teeth. Though selfmade devices are rare in the UK as dental care is accessible, there are still a few reported cases. I would be interested in knowing if other clinicians have encountered patients who have carried out bizarre DIY procedures on their teeth.

V. Egemonye

London

doi: 10.1038/sj.bdj.4811093

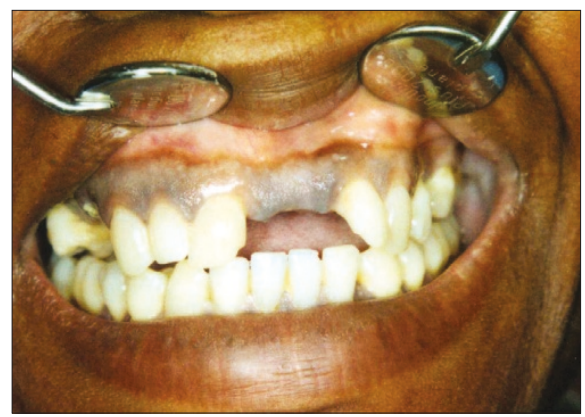

Figure 1

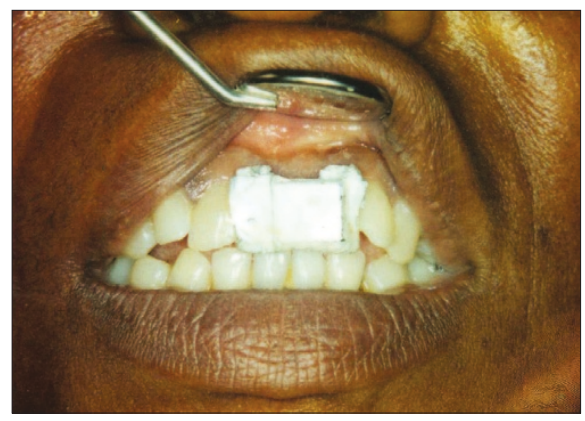

Figure 2 